OPEN ACCESS

Edited by:

Anne Lorant,

Laboratoire de Biologie Moléculaire et Cellulaire du Cancer (LBMCC), Luxembourg

Reviewed by: Souvik Dey,

Jadavpur University, India Akihiro Tomida,

Japanese Foundation For Cancer

Research, Japan

*Correspondence: Xiaobing Tian xiaobing_tian@brown.edu Wafik S. El-Deiry wafik@brown.edu

Specialty section:

This article was submitted to Pharmacology of Anti-Cancer Drugs, a section of the journal

Frontiers in Pharmacology

Received: 26 July 2021 Accepted: 10 September 2021 Published: 24 September 2021

Citation:

Tian X, Zhang S, Zhou L, Seyhan AA, Hernandez Borrero L, Zhang $Y$ and EI-Deiry WS (2021) Targeting the Integrated Stress Response in

Cancer Therapy.

Front. Pharmacol. 12:747837. doi: 10.3389/fphar.2021.747837

\section{Targeting the Integrated Stress Response in Cancer Therapy}

\author{
Xiaobing Tian ${ }^{1,2,3,4 *}$, Shengliang Zhang ${ }^{1,2,3,4}$, Lanlan Zhou ${ }^{1,2,3,4}$, Attila A. Seyhan ${ }^{1,2,3,4}$, \\ Liz Hernandez Borrero ${ }^{1}$, Yiqun Zhang ${ }^{1}$ and Wafik S. El-Deiry ${ }^{1,2,3,4,5 *}$
}

${ }^{1}$ Laboratory of Translational Oncology and Experimental Cancer Therapeutics, Warren Alpert Medical School, Brown University, Providence, RI, United States, ${ }^{2}$ Department of Pathology and Laboratory Medicine, Warren Alpert Medical School, Brown University, Providence, Rl, United States, ${ }^{3}$ Joint Program in Cancer Biology, Lifespan Health System and Brown University, Providence, RI, United States, ${ }^{4}$ Cancer Center at Brown University, Providence, RI, United States, ${ }^{5}$ Hematology/Oncology Division, Department of Medicine, Lifespan Health System and Brown University, Providence, RI, United States

The integrated stress response (ISR) is an evolutionarily conserved intra-cellular signaling network which is activated in response to intrinsic and extrinsic stresses. Various stresses are sensed by four specialized kinases, PKR-like ER kinase (PERK), general control nonderepressible 2 (GCN2), double-stranded RNA-dependent protein kinase (PKR) and heme-regulated elF2a kinase (HRI) that converge on phosphorylation of serine 51 of elF2 $\alpha$. elF2 $\alpha$ phosphorylation causes a global reduction of protein synthesis and triggers the translation of specific mRNAs, including activating transcription factor 4 (ATF4). Although the ISR promotes cell survival and homeostasis, when stress is severe or prolonged the ISR signaling will shift to regulate cellular apoptosis. We review the ISR signaling pathway, regulation and importance in cancer therapy.

Keywords: integrated stress responses, ATF4, CHOP, apoptosis, cancer treatment

\section{INTRODUCTION}

ISR is an evolutionarily conserved intra-cellular signal network activated in response to various intrinsic and extrinsic factors (Figure 1). Extrinsic factors include amino acid depletion, glucose deprivation, viral infection, hypoxia, heme deficiency, ROS (reactive oxygen species) and DNA damage (Pakos-Zebrucka et al., 2016; Clementi et al., 2020; Akman et al., 2021). Cellular intrinsic stresses, such as ER (endoplasmic reticulum) stress, can also activate the ISR (Pakos-Zebrucka et al., 2016). In the context of cancer biology, oncogene activation, such as MYC overexpression, can trigger the ISR (Tameire et al., 2019). Cancer cells with enhanced proliferation have enhanced protein synthesis which leads to a high basal level of the ISR as compared to normal cells (McConkey, 2017; Tameire et al., 2019). This may explain why ISR inducers can selectively target cancer cells.

Various stresses are sensed by four specialized kinases (PERK, GCN2, PKR and HRI) that converge on phosphorylation of serine 51 of eIF2a (Figure 1) (Perkins and Barber, 2004; Wek et al., 2006; Donnelly et al., 2013). Although significant sequence homology exists between these four eIF2 $\alpha$ kinases in their kinase catalytic domains, underlying their common role in phosphorylating eIF2 $\alpha$, each eIF2 $\alpha$ kinase possesses distinct regulatory domains and additional unique features that determine the regulation of these four kinases by signals that activate them (Donnelly et al., 2013). Each kinase responds to distinct environmental and physiological stresses, which reflects their unique regulatory mechanisms (Donnelly et al., 2013). eIF2a phosphorylation causes global reduction of protein synthesis and triggers the translation of specific mRNAs, including ATF4 to help with cell survival and recovery. However, if the stress cannot be reduced, ATF4 regulates an apoptosis program to eliminate the damaged cells (PakosZebrucka et al., 2016; Costa-Mattioli and Walter, 2020). 


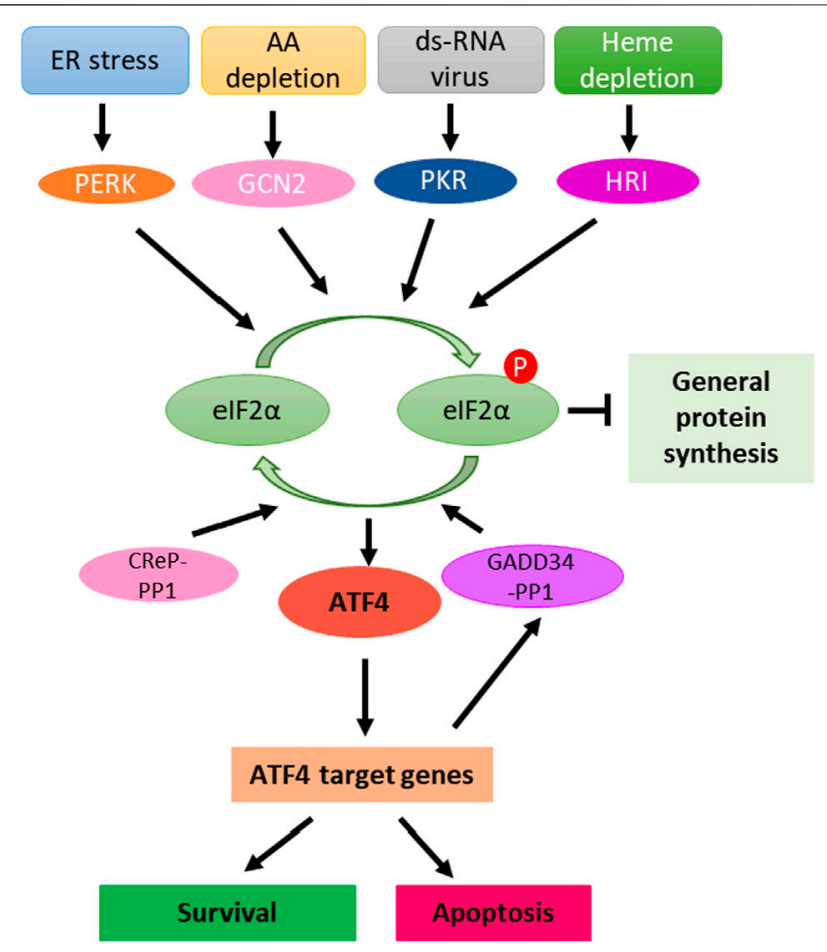

FIGURE 1 | Integrated stress responses signaling pathway. ER stress, mitochondria stress or heme depletion, amino acid deficiency and ds-RNA virus infection activate PERK, HRI, GCN2 and PKR sensor kinases, leading to phosphorylation of elF2 $\alpha$. elF2 $a$ phosphorylation causes global inhibition of protein synthesis but selective translation of ATF4 mRNA. ATF4 binds to DNA targets to regulate the expression of genes that promote cellular adaptation, survival and apoptosis. Feedback regulation of ISR is regulated by constitutively expressed phosphatase complex CReP-PP1 and inducible phosphatase GADD34-PP1, which dephosphorylate elF2 $\alpha$ and attenuate or terminate ISR. AA, Amino acid; ER, Endoplasmic reticulum.

ATF4 plays an important role in communicating pro-survival and pro-apoptotic signals. Once activated, ATF4 regulates transcriptional programs involved in cell survival (antioxidant response, amino acid biosynthesis and autophagy), senescence and apoptosis. The final outcome of ATF4 activation is dependent on the cell type, nature of stressors and duration of the stresses (Figure 1) (Wang et al., 2015; Wortel et al., 2017; Ojha et al., 2019; Tameire et al., 2019).

\section{The Integrated Stress Response and Cell Survival}

The ISR promotes cellular survival signaling by negative regulation of cell death pathways, such as apoptosis. For instance, as a consequence of ER stress, PERK-induced activation of the ISR results in the expression of cIAP1 and cIAP2 (cellular inhibitor of apoptosis proteins) in tumor and non-tumor cells (Hamanaka et al., 2009; Hu et al., 2004; Warnakulasuriyarachchi et al., 2004). Previously, it was demonstrated that restoration of the function of cIAP1 or cIAP2 in $\mathrm{PERK}^{-/-}$murine embryonic fibroblasts during ER stress delays the early onset of ER stress-induced caspase activation and apoptosis seen in these cells (Figure 2) (Hamanaka et al., 2009).

ATF4 has also been demonstrated to facilitate anti-neoplastic agent bortezomib-induced upregulation of anti-apoptotic myeloid cell leukemia-1 (Mcl-1) protein, which is an antiapoptotic Bcl-2 family protein that plays essential roles in multiple myeloma survival and drug resistance in many tumor types (Figure 2) (Hu et al., 2012).

It has been shown that both MCL-1 and cIAPs can suppress apoptosis at different points in the apoptosis pathway that are upstream and downstream of the release of cytochrome $c$ from the mitochondria. Mitochondrial cytochrome $c$ plays a dual function in controlling both cellular energetic metabolism and apoptosis. It has been shown that, upon interacting with apoptotic protease activating factors (Apaf), cytochrome c can trigger the activation cascade of caspases once it is released from the mitochondria into the cytosol (Cai et al., 1998).

It has also been reported that miR-211 is a pro-survival microRNA that regulates CHOP expression in a PERKdependent manner and thus PERK can mediate a pro-survival function by suppressing a stress-dependent expression of $\mathrm{CHOP}$ consequently leading to re-establishment of cellular homeostasis before the initiation of apoptosis (Chitnis et al., 2012). In addition to its beneficial roles in restoring homeostasis, these ISR mechanisms may also contribute to tumor development. For example, an increased miR-211 expression, found to be PERK-dependent, and was reported in mammary carcinoma and mouse models of human B-cell lymphoma (Figure 2) (Chitnis et al., 2012).

Cancer cells use multiple stress response pathways such as the integrated stress response (ISR), cytosolic heat shock response (HSR), and unfolded protein response (UPR) mediated by organelles such as the endoplasmic reticulum (ER) and mitochondria to respond exogenous and endogenous or environmental stresses to evade apoptosis, ensure survival, proliferation, metastatic potential, and maintain cellular homoeostasis (O'Malley et al., 2020). For example, to evade apoptosis and ensure survival, cancer cells may utilize the mitochondrial unfolded protein response (UPRmt) pathway and associated key proteins including chaperones HSP10, HSP60, and mtHSP70 and proteases ClpP and LONP1 to eliminate proteotoxic stress (Figure 2) (O'Malley et al., 2020). Notably, upregulation of HSP60 expression and its upstream regulator ATF5 has been shown to enhance the apoptotic threshold in cancer cells resulting in therapeutic resistance in many cancer types. ATF-5 has been reported to regulate expression of Egr-1, BCL-2, and MCL1 to mediate proliferation and survival in cancer (Dluzen et al., 2011; Liu et al., 2011; Karpel-Massler et al., 2016).

Moreover, in addition to the genes mentioned above many other genes activated in response to ISR (Costa-Mattioli and Walter, 2020), including those encoding ATF4, ATF5 (Zhou et al., 2008); CHOP (C/EBP-homologous protein) (Palam et al., 2011); GADD34 (Growth Arrest And DNA-DamageInducible 34) (Lee et al., 2009); and in neurons, OPHN1 (Oligophrenin-1) (Di Prisco et al., 2014), other genes such as IBTKa (the a isoform of inhibitor of Bruton's tyrosine kinase) (Baird et al., 2014) and NUPR1 (Nuclear protein-1), also play 


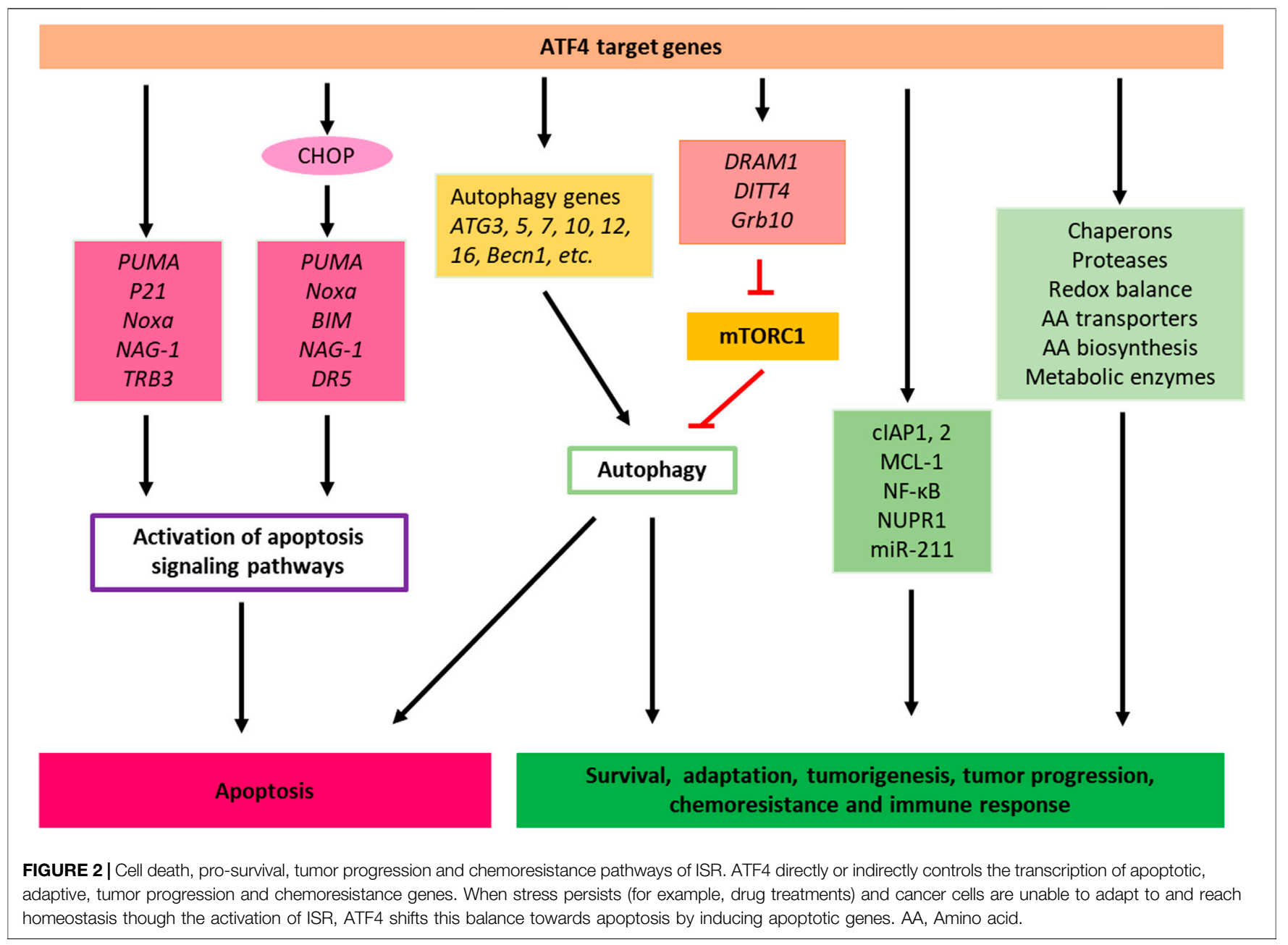

important roles in cell survival. NUPR1 has been found to play an important role in cell stress and stress-related apoptosis (Martin et al., 2021) and inactivation of NUPR1 promotes cell death by coupling ER-stress responses with necrosis (Santofimia-Castaño et al., 2018). More evidences suggest that ATF4 initiates the activity of transcription factor NUPR1. NUPR1 regulates the expression of several metabolic stress-responsive genes, in particular, genes required in cell cycle regulation and DNA repair, as such, NUPR1 also is regarded as pro-survival factors (Figure 2) (Jin et al., 2009; Hamidi et al., 2012).

Another gene activated during the ISR is the IBTKa which is activated during ER stress. IBTKa is a major substrate adaptor for protein ubiquitination and is an essential pro-survival factor (Baird et al., 2014).

Likewise, eIF2 $\alpha$ mediated translational repression has been suggested in activated $\mathrm{B}$ cell NF- $\kappa \mathrm{B}$ pathway induction as a mechanism to protect cells against ER stress (Deng et al., 2004). In a recent study, a pharmacologically activable version of PERK was used to uncouple eIF2 $\alpha$ phosphorylation from stress and it was determined that eIF2 $\alpha$ phosphorylation is both required and adequate to activate both NF- $\kappa \mathrm{B}$ DNA binding and an NF- $\kappa \mathrm{B}$ reporter gene (Deng et al., 2004). Also, HRI has been shown to be involved in NF- $\kappa$ B activation (Abdel-Nour et al., 2019). This study found that the eIF2 $\alpha$ kinase HRI controls NOD1 (Nucleotide-binding oligomerization domain-containing protein 1) signalosome folding and activation through a process requiring eIF2 $\alpha, \mathrm{ATF} 4$, and the heat shock protein HSPB8 (Abdel-Nour et al., 2019). Moreover, HRI/ eIF2a signaling pathway was shown to be required for signaling downstream of the innate immune mediators including NOD2, MAVS (Mitochondrial antiviral-signaling protein), and TRIF (TIR-domain-containing adapter-inducing interferon- $\beta$ ) but dispensable for signaling pathways that rely on MyD88 (Myeloid differentiation primary response 88) or STING (Stimulator of interferon genes) (Figure 2) (Abdel-Nour et al., 2019).

\section{The Integrated Stress Response and Activation of Autophagy}

Autophagy is a highly regulated eukaryotic cellular pathway that plays a major role in the lysosomal degradation of cytoplasmic unfolded proteins, peptides, damaged organelles or cytosolic components while also serving as a means to replenish depleted amino acids for building proteins and to provide energy to a starved cell. Autophagy can be activated by a variety of cellular stresses such as nutrient or growth factor deprivation, hypoxia, reactive oxygen species, DNA damage, protein aggregates, 
damaged organelles, or intracellular pathogens (Pakos-Zebrucka et al., 2016; Clementi et al., 2020; Akman et al., 2021). Autophagy can be activated both via specific, stimulus-dependent manner and more general, stimulus-independent signaling pathways to coordinate different phases of autophagy.

The ISR can modulate cell survival and cell death pathways through the activation of autophagy and the phosphorylation of eIF2 $\alpha$ at S51 appears to be essential for stress-induced autophagy (Pakos-Zebrucka et al., 2016). Autophagy can be integrated with other cellular stress responses through parallel stimulation of autophagy and other stress responses by specific stress stimuli, through dual regulation of autophagy and other stress responses by multifunctional stress signaling molecules, and/or through mutual control of autophagy and other stress responses.

\section{PERK Regulates Autophagy}

Although mechanisms by which phosphorylated eIF2 $\alpha$ induces autophagy are still not completely elucidated, specific extrinsic and intrinsic stresses that lead to the phosphorylation of eIF2 $\alpha$ have been demonstrated to trigger autophagy. For instance, ER stress increases phosphorylation of eIF2 $\alpha$ and ensuing upregulation of certain autophagy receptors including SQSTM1, NBR1, and BNIP3L through PERK (Deegan et al., 2015). Likewise, inhibition of PERK pharmacologically suppresses transcriptional upregulation of these autophagy receptors in mammalian cells (Deegan et al., 2015).

Furthermore, phosphorylation of eIF2 $\alpha$ mediated by PERK increases the conversion of ATG12 and LC3 due to the expression of polyQ72 aggregates in C2C5 cells, which is an essential step for autophagy formation (Kouroku et al., 2007). This PERK-mediated Unfolded Protein Response (UPR) has been shown to regulate autophagy from induction, to vesicle nucleation, phagophore elongation, and maturation (Deegan et al., 2013).

Moreover, it was reported that ER stress due to bluetongue virus infection of cells leads to autophagy through the activation of the PERK-eIF2 $\alpha$ pathway (Lv et al., 2015). The UPR which is initiated in response to the accumulation of misfolded proteins in the ER leading to stress is predominantly an adaptive response to the activation of the ISR. It was shown that UPR protects human tumor cells during hypoxia through regulation of the autophagy genes MAP1LC3B and ATG5 (Rouschop et al., 2010) and this was mediated by PERK phosphorylation of eIF2 $\alpha$. Conversely, abrogation of PERK signaling or expression of mutant eIF2 $\alpha$ S51A which cannot be phosphorylated under the condition of hypoxia reduces the transcription of MAP1LC3B and ATG5 (Rouschop et al., 2010).

IRS-induced autophagy also can lead to cell death. A recent paper reported that compound $\mathrm{SH} 003$ induces autophagy and autophagic cell death through a PERK-eIF2 $\alpha$-ATF4-CHOP signaling pathway in human gastric cancer cells (Figure 2) (Kim et al., 2020).

\section{General Control Non-Derepressible 2 Regulates Autophagy}

Similarly, amino acid deprivation in cancer cells leads to the phosphorylation of eIF $2 \alpha$ mediated by GCN2 which is required for the activation of autophagy (Ye et al., 2010). Notably, while GCN2 knockout cells exhibited decreased LC3 expression, cells with mutant the eIF2 $\alpha$ S51A were not able to activate the processing of LC3 (Ye et al., 2010). Likewise, in the regulation of autophagy induced by amino acid starvation, phosphorylation of eIF2 $\alpha$ at S51 was found to be required in yeast and mouse embryonic fibroblasts (MEFs) (Tallóczy et al., 2002). These findings suggest that eIF2 $\alpha$ phosphorylation at S51 forms the central hub between different stresses and activation of autophagy.

Downstream of eIF2 $a$ phosphorylation, although ATF4 has been implicated to be essential for activation of autophagy, other mechanisms directed from eIF2a phosphorylation other than selective translation of ATF4 mRNA might also be involved in the activation of the autophagy process (Kroemer et al., 2010). It was previously suggested that phosphorylation of eIF2 $\alpha$ might affect the ER in a manner that promotes the physical formation of the isolation membrane. Alternatively, eIF $2 \alpha$ phosphorylation might stimulate autophagy through its effects on the transactivation of autophagy genes. eIF2 $\alpha$ phosphorylation stimulates the selective translation of the ATF4 transcription factor, which stimulates LC3 expression which is essential for sustained autophagy (Milani et al., 2009; Kroemer et al., 2010). Furthermore, although autophagy interaction network components play important roles in vesicle trafficking, protein or lipid phosphorylation and protein ubiquitination and there are direct interactions between eIF2 $\alpha$ subunits and core autophagy proteins, whether these interactions are biologically significant is not clearly understood (Behrends et al., 2010).

Under conditions of ER stress or amino acid deprivation, there is transcriptional upregulation of key autophagy genes mediated by ATF4 including MAP $1 L C 3 B$ and $A T G 5$ which are required for autophagosome biogenesis and function (Deegan et al., 2015; Rzymski et al., 2010; B'Chir et al., 2013). ATF4 can also upregulate the DITT4/REDD1 and DRAM1, which represses the activity of mTORC1, subsequently inducing autophagy (Figure 2) (Kazemi et al., 2007; Whitney et al., 2009; Dennis et al., 2013; Tian et al., 2021).

Furthermore, ATF4 activation in response to amino acid deprivation also directs an autophagy gene transcriptional program by upregulating several autophagy genes such as Atg3, Atg5, Atg7, Atg10, Atg12, Atg16, Becn1, Gabarap, Gabarapl2, Map1lc3b, and Sqstm1 (Figure 2) (B'Chir et al., 2013). Through the stimulation of key genes involved in autophagy, the ISR mediates the up-regulation of the autophagic process in an attempt to resolve the stress induced by amino acid deprivation. This is accomplished by the increased recycling of cytoplasmic components and sustaining the biosynthetic capacity of the cell and cellular ATP concentrations. The increased autophagic function leads to increased amino acid levels in ER required for de novo protein biosynthesis and similarly leads to increased levels of substrates including free fatty acids and amino acids for the tricarboxylic acid cycle (Rzymski et al., 2009; Ye et al., 2010).

However, it was also shown that a variety of autophagy genes can have a varying degree of reliance on ATF4 and CHOP signaling and that the transcriptional upregulation of such 
genes is regulated by the ratio of ATF4 and CHOP proteins that are bound to a particular promoter, and thus fine-tuning the expression of autophagy genes depending on the needs of the cell (B'Chir et al., 2013).

Studies on the effect of proteasome inhibition on survival signaling by the ISR have revealed that suppression of proteasome function pharmacologically using antineoplastic agent bortezomib results in depletion of amino acids in the ER required for protein synthesis leading to the activation of the ISR via GCN2 stress sensor (Suraweera et al., 2012).

Amino acid depletion as a result of proteasome inhibition also activates autophagy through $\mathrm{mTOR}$ in an attempt to restore amino acid homeostasis (Suraweera et al., 2012). Conversely, exogenous supplementation of essential amino acids depleted by the inhibition of proteasome function inhibition attenuates the phosphorylation of eIF2 $\alpha$ and down-regulates autophagy (Suraweera et al., 2012). As such, depletion of amino acids by proteasome inhibition establishes a link between ISR activation and induction of autophagy in an attempt to sustain the survival of the cell.

Heme-Regulated elF2 $\alpha$ Kinase Regulates Autophagy Although the other eIF2 $\alpha$ kinases are present across different tissues, eIF2 $\alpha$ kinase HRI is more specific to erythroid cells and plays a major role in erythrocyte differentiation during erythropoiesis (Suraweera et al., 2012). eIF2a kinase HRI mediates the translation of globin mRNAs with the availability of heme for the production of hemoglobin. By doing so, HRI protects erythroid cells from the increase of toxic globin aggregates under conditions of iron deficiency (Bruns and London, 1965; Chefalo et al., 1998; Han et al., 2001; Suragani et al., 2012). Other stresses such as arsenite-induced oxidative stress, heat shock, osmotic stress, $26 \mathrm{~S}$ proteasome inhibition, and nitric oxide also were shown to activate HRI (Han et al., 2001; Lu et al., 2001; McEwen et al., 2005; Yerlikaya et al., 2008; Ill-Raga et al., 2015) and activation of HRI by these stresses is independent of heme and heat shock proteins HSP90 and HSP70 facilitates this process; however, the exact mechanism of HRI activation is still being studied (Lu et al., 2001).

A recent report demonstrated that HRI controls autophagy to clear cytosolic protein aggregates (Mukherjee et al., 2021). In that study, researchers found that the eIF2 $\alpha$ kinase HRI induced a cytosolic unfolded protein response to prevent aggregation of innate immune signalosomes. Furthermore, they demonstrated that HRI controls autophagy to clear cytosolic protein aggregates when the ubiquitin-proteasome system is inhibited (Mukherjee et al., 2021).

Growth factor receptor-bound protein 10 (Grb10) is regulated by ATF4 (Zhang et al., 2018). the HRI-eIF2aP-ATF4 pathway suppresses mTORC1 signaling through Grb10 specifically in the erythroid lineage (Figure 2) (Zhang et al., 2018). mTORC1 was shown to act as a master regulator of autophagy since inhibition of mTORC1 was required to initiate the autophagy process (Dossou and Basu, 2019). It was also shown that mTORC1 directly regulates the downstream steps of the autophagy process, such as the nucleation, autophagosome elongation, autophagosome maturation and termination (Dossou and Basu, 2019).

\section{PKR Regulates Autophagy}

Talloczy, Z. et al. report that PKR acts as a potent inducer of autophagy during viral infection (Tallóczy et al., 2006). Also, two papers indicate that PKR is very important for the autophagic degradation of herpes simplex virions both in vitro and in vivo (Tallóczy et al., 2006; Orvedahl et al., 2007). In these settings, PKR was shown to operate upstream of Beclin 1 (Tallóczy et al., 2006).

Shen, S. et al. report that STAT3 inhibitors (JSI-124, WP1066 and Stattic) caused the disruption of inhibitory STAT3-PKR interactions in human osteosarcoma U2OS cells, resulting in release and activation of PKR. PKR phosphorylates eIF2 $\alpha$, which regulates the activity of Beclin $1 / \mathrm{Vps} 34$ complex and facilitates autophagy induction (Figure 3) (Shen et al., 2012).

Pathogenic bacterium Mycobacterium tuberculosis (Mtb) infection induces the activation of PKR and PKR-mediated autophagy in macrophage. Sustained expression and activation of PKR reduced the intracellular survival of $\mathrm{Mtb}$, which could be enhanced by Interferon gamma (IFN $\gamma$ ) treatment (Smyth et al., 2020).

\section{The Integrated Stress Response and Cell Death}

The cell death pathways are complex and can be exploited by cancer therapeutic agents (Carneiro and El-Deiry, 2020). When stress persists and cells are unable to reach homeostasis despite the activation of stress response pathways, ATF4 can induce the transcriptional activation of apoptotic genes encoding $\mathrm{CHOP}$ (DDIT3) (Harding et al., 2000), TRB3 (Tribbles homolog 3) (Ohoka et al., 2005), and pro-apoptotic BH3-only proteins including PUMA (p53 upregulated modulator of apoptosis), Noxa (Phorbol-12-myristate-13-acetate-induced protein 1) and BIM (Bcl-2 Interacting mediator of cell death), thus leading to cell death (Galehdar et al., 2010; Altman et al., 2009; Puthalakath et al., 2007). ATF4 has been shown to regulate Noxa at the transcriptional level and this leads to the induction of apoptosis (Sharma et al., 2018; Núñez-Vázquez et al., 2021). Overall, through the induction of ATF4, this transcription factor appears to mainly trigger the intrinsic apoptosis by modulating the expression of pro- and anti-apoptotic BCL-2 family members. Interestingly, in the case of CHOP activation, induction of DR5 (Death receptor 5) mediated apoptosis appeared to be DR5 ligand binding independent and involving the engagement of FADD (Fas-associated protein with death domain) and caspase-8 (Figure 2) (Lu et al., 2014; Li et al., 2015).

Additional stresses such as those resulting from decreased mitochondrial translation (Sasaki et al., 2020) as well as the generation of reactive oxygen species (Kasai et al., 2019) have been shown to induce ATF4 expression. In the case of sustained mitochondrial deficiency, ATF4 response has been reported to lead to p53-mediated apoptosis (Evstafieva et al., 2014). Reactive oxygen species generated by Fenretinide treatment in neuroblastoma cells activates ATF4 leading to the induction of Noxa ultimately leading to apoptosis (Nguyen et al., 2019). In multiple myeloma cells, sensitivity to bortezomib treatment was associated with higher expression of ATF4 and loss of its expression lead to lower levels of Noxa, CHOP and DR5 


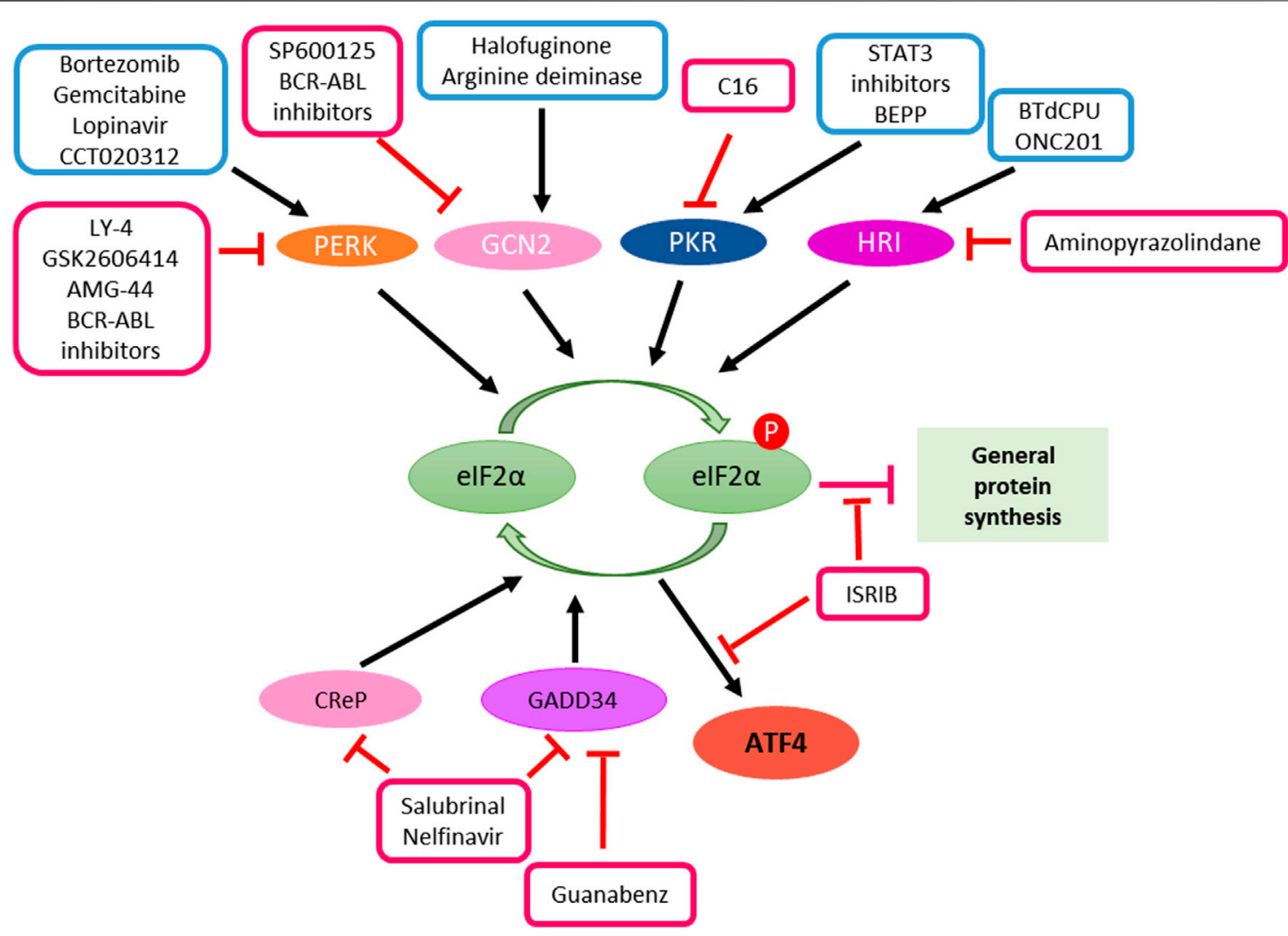

FIGURE 3 | Manipulation of ISR in cancer therapy. ATF4 induction can be achieved either through kinase activators such as bortezomib, gemcitabline, lopinavir, CCT020312, halofuginone, arginine deiminase, STAT3 inhibitors, BEPP, BTdCPU and ONC201 or the inhibitors of phosphatases such as salubrinal, guanabenz and nelfinavir. In the case of ISR promotes cancer cell survival and resistant to therapeutic treatments, inhibition of ATF4 can be achieved by kinase inhibitors such as LY-4, GSK2606414, AMG-44, BCR-ABL inhibitors, SP600125, C16 and aminopyranzolindane or compound ISRIB downstream of elF2 $\alpha$ phosphorylation.

(Narita et al., 2015). Recent work from our lab has also implicated ATF4 responsible for the induction of p53-target genes PUMA, Noxa, NAG-1(Nonsteroidal anti-inflammatory drug-activated gene-1)and DR5 upon treatment with prodigiosin analogue PG3-Oc (Figure 2) (Tian et al., 2021).

The aforementioned studies involve the induction of the ISR machinery in addition to distinct components of autophagy, cell cycle, and/or apoptosis pathway. This reflects the complexity of the interplay of these cellular pathways which remains underscored and likely to be context-dependent. Recent work has focused on posttranslational modifications of ATF4 and how these affect the transcriptional control and cellular response. ATF4 has numerous sites that can be post-translationally modified including phosphorylation at various threonine and serine sites, methylation at arginine 239, and ubiquitination and acetylation at lysine residues (Wortel et al., 2017). These post-translational modifications affect ATF4 protein stability, activation and interaction with other proteins. In the case of apoptosis, methylation at arginine 239 by methyl transferase PRMT1 was found to be associated with the transcription of genes related to apoptosis (Yuniati et al., 2016). Further insight into ATF4 activation may shed light on understanding the context of how these transcription factors respond to stress and the biological outcome they ultimately trigger in both normal and cancer cells. Importantly, this will aid the intervention of novel therapies, the use of the ISR as potential biomarker for predicting therapy response and the combination of therapies that induce ATF4-mediated apoptosis. An example of therapy combination has been observed in in vivo neuroblastoma preclinical models with the BCL-2 inhibitor Venetoclax and Fenretinide (Nguyen et al., 2019). This studied combination highlighted the use of BCL-2 expression as a biomarker for neuroblastoma patients. A separate study in multiple myeloma suggested the use of ATF4 as a predictive therapy response biomarker for bortezomib and dexamethasone combination treatment (Narita et al., 2015). These studies exemplified the clinical translational applicability of exploiting the ISR in cancer therapy and highlight its warrant understanding to predict cancer types that will benefit from ISR modulating therapies.

\section{Dual Roles of the Integrated Stress Response in Cancer}

The ISR plays different roles in tumorigenesis and tumor progression in different types of tumors. Hypoxia is a common phenomenon in solid tumors. It may induce apoptosis of tumor cells or tumor cells may develop the ability to adapt to the hypoxia or anoxic environment. Hypoxia can induce ISR gene expression in transformed mouse embryonic fibroblasts and the activated ER stress response confers resistance 
to apoptosis induced by hypoxia and thus facilitates tumor growth (Ameri et al., 2004). ISR mediator ATF4 is induced by anoxia in breast cancer cell lines (Ameri et al., 2004). The activated ISR plays an essential role in the adaptation to hypoxic stress allowing tumor cell survival under stress and is associated with resistance to therapy (Blais et al., 2004; Rouschop et al., 2013).

It was found that loss of extracellular matrix (ECM) attachment stimulates ISR signaling in vitro. And the activation of ISR further plays a critical role in resistance to anoikis and is required for metastasis (Dey et al., 2015). The ISR also has impact on the tumor microenvironment. Tumor cells undergoing ER stress can transmit ER stress to myeloid cells contributing to a pro-inflammatory tumor microenvironment, thus facilitating tumor progression (Mahadevan et al., 2011).

The role of ISR may be complex in tumors. In medulloblastoma, the ISR is activated, and the decreased ISR via gene manipulation attenuates medulloblastoma formation. Moderately enhanced ISR by gene manipulation noticeably increased the incidence of medulloblastoma, whereas a strongly enhanced ISR significantly decreased the incidence of medulloblastoma in vivo. Thus, the ISR plays dual roles in medulloblastoma formation (Stone et al., 2016).

Activation of the ISR is correlated with resistance to chemotherapy in pancreatic cancer and BRAF-mutated melanoma. Gemcitabine can induce ISR and the antiapoptotic pro-survival factors via the ISR pathway in pancreatic cancer cell line and the combination of gemcitabine + ISRIB which inhibits ISR induce more apoptosis in vivo (Palam et al., 2015). In BRAFmutated melanoma, chronic ER stress involving induction of the ISR signaling pathway activates autophagy which contributes chemoresistance (Corazzari et al., 2015).

Triggering ISR can be a therapeutic strategy against cancer, since the ISR can induce apoptosis. ONC201 kills solid tumors by triggering ISR-dependent ATF4 activation and activation of the TRAIL-DR5 apoptotic pathway (Kline et al., 2016). In breast cancer, GBM and DMG cell lines, ONC201 induces ISR, TRAILDR5 and ultimately apoptosis (Zhang et al., 2021). The apoptosis increases with the enhancement of ISR induction by tazemetostat. The knockdown of ATF4 in GBM cell line reduced the apoptosis induced by ONC201 and the combination of ONC201 with tazemetostat or vorinostat remarkably. Therefore, induction of ISR can play an essential role in cell death of cancer cells. Apoptosis induced by ISR activation was also observed in AML cells (Ishizawa et al., 2016).

The combination of mitochondrial uncoupler niclosamide ethanolamine and dopamine receptor antagonist domperidone or TCAs induces ISR and leas to apoptosis in multiple cancer cell lines including CRC, GBM (Glioblastoma multiforme) and PDAC (Pancreatic ductal adenocarcinoma) cell lines (Hartleben et al., 2021). Even without inducing apoptosis, the ISR is induced by ONC201 in cancer cells exhibiting decreased cell proliferation (Kline et al., 2016).

The ISR contributes to drug sensitivity of cancer cells. Activation of the ISR in HER2+breast cancer contributes the sensitivity to Trastuzumab in vivo. Increased expression of the ISR mediator eIF2 $\alpha$-P predicts a better response of patients with
HER2+ metastatic breast cancer to Trastuzumab therapy (Darini et al., 2019). Proteasome inhibitors are known to activate the ISR and lower expression of ISR markers thus implicating shorter progression-free survival in multiple myeloma (Obeng et al., 2006).

It was reported that ISR promotes the expression of potential target for immunotherapy (Obiedat et al., 2020). Thus, ISR may play a role in cancer immunotherapy.

On the one hand, activation of ISR plays a role in cancer therapy. On the other, Inhibition of ISR activation can increase the vulnerability of cancer cells. BCR-ABL inhibition prevents activation of ISR in K562 cell line derived from a chronic myeloid leukemia (CML) patient and makes the tumor cells more vulnerable to metabolic stress (Kato et al., 2018). Summaries of the mentioned cases and drugs can be found in the Table $\mathbf{1}$, Table 2 and Figure 3.

\section{Manipulation of Integrated Stress Response in Cancer Therapy}

The ISR takes a dual role in cell survival and cell death. Enhance or inhibition of ISR signaling via targeting ISR components is a promising strategy for cancer therapy (Figure 3). Among the components in ISR signaling, eIF2 $\alpha$ is a core component and an important focused for cancer therapy.

\section{Enhanced Integrated Stress Response Signaling via Increased elF2 $\alpha$ Kinase}

eIF $2 \alpha$ is a core component of the ISR, and phosphorylation of eIF $2 \alpha$ is regulated by upstream regulators. One of approaches is to phosphorylate eIF $2 \alpha$ by increasing eIF2a kinases upstream of eIF2 $\alpha$, such as GCN2, PERK, and HRI (PakosZebrucka et al., 2016; Chu et al., 2021). Most of eIF2a activators are small molecules. Halofuginone and arginine deiminase are GCN2 activators (Long et al., 2013; Castilho et al., 2014). BTdCPU and ONC201 activates HRI (Kline et al., 2016; Chen et al., 2011). Bortezomib, gemcitabine, lopinavir and CCT020312 selectively activates PERK (Narita et al., 2015; Palam et al., 2015; Obeng et al., 2006; Obiedat et al., 2020; Stockwell et al., 2012). BEPP works on PKR activation (Figure 3) (Hu et al., 2009). These elF2a kinase activators have been studied in cancer therapy. For example, Halofuginone and arginine deiminase were found to inhibit tumor growth, development and metastasis either as single agents or in combination with 5-FU or radiation (Abramovitch et al., 2004; Kim et al., 2009; Cook et al., 2010; Spector et al., 2010; Lamora et al., 2015; Brin et al., 2018; Singh et al., 2019; Wang et al., 2020; Huang and Hu, 2021). Our laboratory has identified two small molecules PG3-Oc (Tian et al., 2021) and ONC201 (Kline et al., 2016; Ishizawa et al., 2016) that suppress tumor growth through increased ISR signaling. These drugs enhance ISR signaling via activation of eIF2 $\alpha$ kinases, and sequentially enhance or sustain eIF2a phosphorylation.

Another approach for eIF $2 \alpha$ phosphorylation is to prevent eIF2 $\alpha$ dephosphorylation from eIF2 $\alpha$ phosphatase. GADD34 (PPP1R15A) and $\mathrm{CReP}$ recruit phosphatase PP1 to 
TABLE 1 | The dual roles of ISR in various cancers.

Role of ISR in

cancers

Mediator of ISR is up-regulated in anoxic tumor cells

Mediator of ISR is up-regulated in hypoxic tumor cells

Adaptation to hypoxia

Promotes survival of therapy-resistant hypoxic tumor cells

Contribute to the resistance to anoikis and promote metastasis

ER stress is transmitted from tumor cells to myeloid cells and then facilitate tumor progression

Increase or decrease the incidence of tumor

Contributes to chemoresistance

Contributes drug sensitivity to Trastuzumab
Cancer type

Breast cancer Ishizawa et al. (2016)

Cervical cancer Hartleben et al. (2021)

Glioblastoma and colorectal cancer Darini et al. (2019)

Glioblastoma Darini et al. (2019)

Fibrosarcoma Obeng et al. (2006

Prostate cancer Obiedat et al. (2020)

Medulloblastoma Kato et al. (2018)

BRAF mutated melanoma Long et al. (2013)

HER2+ breast cancer Lamora et al. (2015)

TABLE 2 | Effects of ISR compounds in the treatments of cancers.

\begin{tabular}{|c|c|c|}
\hline Compounds & Effect on ISR & $\begin{array}{l}\text { Effects of ISR on } \\
\text { tumor cells }\end{array}$ \\
\hline Gemcitabine & Induce ISR & Contributes to chemoresistance \\
\hline Bortezomib & Induce ISR & Contributes drug sensitivity \\
\hline ONC201 & Induce ISR & Reduce cell-viability \\
\hline ONC201 & Induce ISR & Induce apoptosis \\
\hline $\begin{array}{l}\text { Mitochondrial uncoupler niclosamide ethanolamine }+ \\
\text { dopamine receptor antagonist domperidone or tricyclic } \\
\text { antidepressants (TCAs) }\end{array}$ & Induce ISR & Induce apoptosis \\
\hline Nelfinavir and lopinavir & Induce ISR & $\begin{array}{l}\text { Promote the expression of } \\
\text { potential target for immunotherapy }\end{array}$ \\
\hline BCR-ABL inhibitors & $\begin{array}{l}\text { Prevent ISR } \\
\text { activation }\end{array}$ & Enhance apoptosis \\
\hline
\end{tabular}

Pancreatic cancer Palam et al. (2015)

Multiple myeloma Obeng et al. (2006); Narita et al. (2015) Lung cancer, thyroid cancer, prostate cancer Kline et al. (2016)

Colorectal cancer, breast cancer, glioblastoma, diffuse midline glioblastoma, AML Kline et al. (2016); Ishizawa et al. (2016); Zhang et al. (2021)

Colorectal cancer, glioblastoma and PDAC Hartleben et al. (2021)

Melanoma Obiedat et al. (2020)

CML Kato et al. (2018)
phosphorylated-eIF2 $\alpha$ and this results in dephosphorylation of eIF2 $\alpha$. Salubrinal is the first small molecule discovered to inhibit eIF2 $\alpha$ dephosphorylation via both GADD34 and CReP (Boyce et al., 2005). Inhibition of GADD34 activity by Guanabenz or its derivatives results in high levels of eIF2a Phosphorylation (Tsaytler et al., 2011). Different from Guanabenz, Nelfinavir increases phosphorylation of eIF2 $\alpha$ by downregulating CReP in addition to it effect on GADD34 (De Gassart et al., 2016). Guanabenz has been found to sensitize glioblastoma cancer cells to sunitinib in combinatorial treatment (Figure 3) (Ho et al., 2021).

\section{Inhibition of Integrated Stress Response Signaling by Reduction of elF2 $\alpha$ Kinase}

Inhibition of ISR signaling may overcome drug resistance in cancer. One of the approaches is to inhibit eIF2a kinase upstream of eIF2 $\alpha$. Most of these kinase inhibitors compete with ATP to block their kinase domain. SP600125 and BCRABL inhibitors inactivate GCN2 (Kato et al., 2018; Robert et al., 2009). Amino-pyrazolindine inhibits HRI (Rosen et al., 2009). Imidazolo-oxindole PKR inhibitor C16 specifically inhibits PKR (Jammi et al., 2003). LY-4, AMG-44, BCR-ABL inhibitors and GSK2606414 inactivate PERK (Tameire et al., 2019; Kato et al., 2018; Axten et al., 2012; Mohamed et al., 2020). They bind to the eIF2 $\alpha$ kinase in an ATP-competitive manner, result in inhibition of kinase activity, and reduce the phosphorylation of eIF $2 \alpha$. Another approach is to terminate eIF $2 \alpha$ signaling downstream of eIF2a. Small-molecule ISRIB prevents the formation of stress granules caused by eIF2 $\alpha$ phosphorylation, thus, impairing ATF4 synthesis (Figure 3) (Sidrauski et al., 2015).

\section{Targeting Integrated Stress Response in Combination of Immunotherapy}

High levels of PD-L1 on the cancer cell surface allows evasion from $\mathrm{T}$ cell attack by binding to the $\mathrm{PD}-1$ receptor on $\mathrm{T}$ cells. Disruption of the PD-1/PD-L1 checkpoint can result in cytotoxic $\mathrm{T}$ cell killing of tumors. The ISR was found to increase PD-L1 translation in human cancers. Suresh et al. (2020) The increased PD-L1 suppress anti-tumor immune responses. PERK signaling was found to suppress immune responses by increasing tumor-myeloid-derived suppressor cells (MDSC). PERK blockade transforms MDSC's into myeloid cells that activate anti-tumor CD8+ T-cell immunity in the tumor microenvironment. AMG-44, a PERK inhibitor, in combination with Anti-PD-L1 showed a synergistic anti-tumor effect in B16 tumor-bearing mice model (Figure 3) (Mohamed et al., 2020). These studies suggest that PERK inhibitors enhance the antitumor efficacy of immune checkpoint inhibitors. Therefore, targeting ISR in combination 
with immune checkpoint is an innovational strategy for cancer therapy.

\section{CONCLUSION}

The ISR is a double-edged sword with pro-survival and pro-death activities that may impact on tumor progression and response to therapy. Our approach for therapeutic targeting of cell death pathways has led us to uncover the ISR as a critical signaling component and target of drug candidates. The fact that the ISR can lead to alternative cell fates depending on cellular context suggests that greater efforts need to be directed at understanding its regulation and finding new ways for its modulation. The ISR holds promise for cancer therapy development.

\section{REFERENCES}

Abdel-Nour, M., Carneiro, L. A. M., Downey, J., Tsalikis, J., Outlioua, A., Prescott, D., et al. (2019). The Heme-Regulated Inhibitor Is a Cytosolic Sensor of Protein Misfolding that Controls Innate Immune Signaling. Science 365 (6448). doi:10.1126/science.aaw4144

Abramovitch, R., Itzik, A., Harel, H., Nagler, A., Vlodavsky, I., and Siegal, T. (2004). Halofuginone Inhibits Angiogenesis and Growth in Implanted Metastatic Rat Brain Tumor Model-Aan MRI Study. Neoplasia 6 (5), 480-489. doi:10.1593/ neo. 03520

Akman, M., Belisario, D. C., Salaroglio, I. C., Kopecka, J., Donadelli, M., De Smaele, E., et al. (2021). Hypoxia, Endoplasmic Reticulum Stress and Chemoresistance: Dangerous Liaisons. J. Exp. Clin. Cancer Res. 40 (1), 28. doi:10.1186/s13046020-01824-3

Altman, B. J., Wofford, J. A., Zhao, Y., Coloff, J. L., Ferguson, E. C., Wieman, H. L., et al. (2009). Autophagy Provides Nutrients but Can lead to Chop-dependent Induction of Bim to Sensitize Growth Factor-Deprived Cells to Apoptosis. Mol. Biol. Cel. 20 (4), 1180-1191. doi:10.1091/mbc.e08-08-0829

Ameri, K., Lewis, C. E., Raida, M., Sowter, H., Hai, T., and Harris, A. L. (2004). Anoxic Induction of ATF-4 through HIF-1-independent Pathways of Protein Stabilization in Human Cancer Cells. Blood 103 (5), 1876-1882. doi:10.1182/ blood-2003-06-1859

Axten, J. M., Medina, J. R., Feng, Y., Shu, A., Romeril, S. P., Grant, S. W., et al. (2012). Discovery of 7-Methyl-5-(1-\{[3-(trifluoromethyl)phenyl]acetyl\}-2,3Dihydro-1h-Indol-5-Yl)-7h-Pyrrolo[2,3-D]pyrimidin-4-Amine (GSK2606414), a Potent and Selective First-In-Class Inhibitor of Protein Kinase R (PKR)-like Endoplasmic Reticulum Kinase (PERK). J. Med. Chem. 55 (16), 7193-7207. doi:10.1021/jm300713s

B'Chir, W., Maurin, A. C., Carraro, V., Averous, J., Jousse, C., Muranishi, Y., et al. (2013). The eIF2 a/ATF4 Pathway Is Essential for Stress-Induced Autophagy Gene Expression. Nucleic Acids Res. 41 (16), 7683-7699. doi:10.1093/nar/ gkt563

Baird, T. D., Palam, L. R., Fusakio, M. E., Willy, J. A., Davis, C. M., McClintick, J. N., et al. (2014). Selective mRNA Translation during eIF2 Phosphorylation Induces Expression of IBTKa. Mol. Biol. Cel. 25 (10), 1686-1697. doi:10.1091/mbc.E1402-0704

Behrends, C., Sowa, M. E., Gygi, S. P., and Harper, J. W. (2010). Network Organization of the Human Autophagy System. Nature 466 (7302), 68-76. doi:10.1038/nature09204

Blais, J. D., Filipenko, V., Bi, M., Harding, H. P., Ron, D., Koumenis, C., et al. (2004). Activating Transcription Factor 4 Is Translationally Regulated by Hypoxic Stress. Mol. Cel Biol. 24 (17), 7469-7482. doi:10.1128/ MCB.24.17.7469-7482.2004

Boyce, M., Bryant, K. F., Jousse, C., Long, K., Harding, H. P., Scheuner, D., et al. (2005). A Selective Inhibitor of eIF2alpha Dephosphorylation Protects Cells from ER Stress. Science 307 (5711), 935-939. doi:10.1126/science.1101902

\section{AUTHOR CONTRIBUTIONS}

All authors listed have made a substantial, direct, and intellectual contribution to the work and approved it for publication.

\section{FUNDING}

WE-D. is an American Cancer Society Research Professor and is supported by the Mencoff Family University Professorship at Brown University. This work was supported by an NIH grant (CA173453) and a grant from the Warren Alpert Foundation to WE-D. This work was supported by the Teymour Alireza $\mathrm{P}^{\prime} 98$, $\mathrm{P}^{\prime} 00$ Family Cancer Research Fund established by the Alireza Family.

Brin, E., Wu, K., Dagostino, E., Meng-Chiang Kuo, M., He, Y., Shia, W. J., et al. (2018). TRAIL Stabilization and Cancer Cell Sensitization to its Pro-apoptotic Activity Achieved through Genetic Fusion with Arginine Deiminase. Oncotarget 9 (97), 36914-36928. doi:10.18632/oncotarget.26398

Bruns, G. P., and London, I. M. (1965). The Effect of Hemin on the Synthesis of Globin. Biochem. Biophys. Res. Commun. 18, 236-242. doi:10.1016/0006$291 x(65) 90746-1$

Cai, J., Yang, J., and Jones, D. P. (1998). Mitochondrial Control of Apoptosis: the Role of Cytochrome C. Biochim. Biophys. Acta. 1366 (1-2), 139-149. doi:10.1016/s0005-2728(98)00109-1

Carneiro, B. A., and El-Deiry, W. S. (2020). Targeting Apoptosis in Cancer Therapy. Nat. Rev. Clin. Oncol. 17 (7), 395-417. doi:10.1038/s41571-020-0341-y

Castilho, B. A., Shanmugam, R., Silva, R. C., Ramesh, R., Himme, B. M., and Sattlegger, E. (2014). Keeping the eIF2 Alpha Kinase Gcn2 in Check. Biochim. Biophys. Acta. 1843 (9), 1948-1968. doi:10.1016/j.bbamcr.2014.04.006

Chefalo, P. J., Oh, J., Rafie-Kolpin, M., Kan, B., and Chen, J. J. (1998). Hemeregulated eIF-2alpha Kinase Purifies as a Hemoprotein. Eur. J. Biochem. 258 (2) 820-830. doi:10.1046/j.1432-1327.1998.2580820.x

Chen, T., Ozel, D., Qiao, Y., Harbinski, F., Chen, L., Denoyelle, S., et al. (2011). Chemical Genetics Identify eIF2 $\alpha$ Kinase Heme-Regulated Inhibitor as an Anticancer Target. Nat. Chem. Biol. 7 (9), 610-616. doi:10.1038/nchembio.613

Chitnis, N. S., Pytel, D., Bobrovnikova-Marjon, E., Pant, D., Zheng, H., Maas, N. L., et al. (2012). miR-211 Is a Prosurvival microRNA that Regulates Chop Expression in a PERK-dependent Manner. Mol. Cel. 48 (3), 353-364. doi:10.1016/j.molcel.2012.08.025

Chu, H. S., Peterson, C., Jun, A., and Foster, J. (2021). Targeting the Integrated Stress Response in Ophthalmology. Curr. Eye Res. 46 (8), 1075-1088. doi:10.1080/02713683.2020.1867748

Clementi, E., Inglin, L., Beebe, E., Gsell, C., Garajova, Z., and Markkanen, E. (2020). Persistent DNA Damage Triggers Activation of the Integrated Stress Response to Promote Cell Survival under Nutrient Restriction. BMC Biol. 18 (1), 36. doi:10.1186/s12915-020-00771-x

Cook, J. A., Choudhuri, R., Degraff, W., Gamson, J., and Mitchell, J. B. (2010). Halofuginone Enhances the Radiation Sensitivity of Human Tumor Cell Lines. Cancer Lett. 289 (1), 119-126. doi:10.1016/j.canlet.2009.08.009

Corazzari, M., Rapino, F., Ciccosanti, F., Giglio, P., Antonioli, M., Conti, B., et al. (2015). Oncogenic BRAF Induces Chronic ER Stress Condition Resulting in Increased Basal Autophagy and Apoptotic Resistance of Cutaneous Melanoma. Cell Death Differ. 22 (6), 946-958. doi:10.1038/cdd.2014.183

Costa-Mattioli, M., and Walter, P. (2020). The Integrated Stress Response: From Mechanism to Disease. Science 368 (6489). doi:10.1126/science.aat5314

Darini, C., Ghaddar, N., Chabot, C., Assaker, G., Sabri, S., Wang, S., et al. (2019). An Integrated Stress Response via PKR Suppresses HER2+ Cancers and Improves Trastuzumab Therapy. Nat. Commun. 10 (1), 2139. doi:10.1038/ s41467-019-10138-8

De Gassart, A., Bujisic, B., Zaffalon, L., Decosterd, L. A., Di Micco, A., Frera, G., et al. (2016). An Inhibitor of HIV-1 Protease Modulates Constitutive eIF2a 
Dephosphorylation to Trigger a Specific Integrated Stress Response. Proc. Natl. Acad. Sci. U S A. 113 (2), E117-E126. doi:10.1073/pnas.1514076113

Deegan, S., Koryga, I., Glynn, S. A., Gupta, S., Gorman, A. M., and Samali, A. (2015). A Close Connection between the PERK and IRE Arms of the UPR and the Transcriptional Regulation of Autophagy. Biochem. Biophys. Res. Commun. 456 (1), 305-311. doi:10.1016/j.bbrc.2014.11.076

Deegan, S., Saveljeva, S., Gorman, A. M., and Samali, A. (2013). Stress-induced SelfCannibalism: on the Regulation of Autophagy by Endoplasmic Reticulum Stress. Cell Mol Life Sci. 70 (14), 2425-2441. doi:10.1007/s00018-012-1173-4

Deng, J., Lu, P. D., Zhang, Y., Scheuner, D., Kaufman, R. J., Sonenberg, N., et al. (2004). Translational Repression Mediates Activation of Nuclear Factor Kappa B by Phosphorylated Translation Initiation Factor 2. Mol. Cel Biol. 24 (23), 10161-10168. doi:10.1128/MCB.24.23.10161-10168.2004

Dennis, M. D., McGhee, N. K., Jefferson, L. S., and Kimball, S. R. (2013). Regulated in DNA Damage and Development 1 (REDD1) Promotes Cell Survival during Serum Deprivation by Sustaining Repression of Signaling through the Mechanistic Target of Rapamycin in Complex 1 (mTORC1). Cell Signal. 25 (12), 2709-2716. doi:10.1016/j.cellsig.2013.08.038

Dey, S., Sayers, C. M., Verginadis, I. I., Lehman, S. L., Cheng, Y., Cerniglia, G. J., et al. (2015). ATF4-dependent Induction of Heme Oxygenase 1 Prevents Anoikis and Promotes Metastasis. J. Clin. Invest. 125 (7), 2592-2608. doi:10.1172/JCI78031

Di Prisco, G. V., Huang, W., Buffington, S. A., Hsu, C. C., Bonnen, P. E., Placzek, A. N., et al. (2014). Translational Control of mGluR-dependent Long-Term Depression and Object-Place Learning by eIF2a. Nat. Neurosci. 17 (8), 1073-1082. doi:10.1038/nn.3754

Dluzen, D., Li, G., Tacelosky, D., Moreau, M., and Liu, D. X. (2011). BCL-2 Is a Downstream Target of ATF5 that Mediates the Prosurvival Function of ATF5 in a Cell Type-dependent Manner. J. Biol. Chem. 286 (9), 7705-7713. doi:10.1074/jbc.M110.207639

Donnelly, N., Gorman, A. M., Gupta, S., and Samali, A. (2013). The eIF2a Kinases: Their Structures and Functions. Cel Mol Life Sci. 70 (19), 3493-3511. doi:10.1007/s00018-012-1252-6

Dossou, A. S., and Basu, A. (2019). The Emerging Roles of mTORC1 in Macromanaging Autophagy. Cancers (Basel) 11 (10), 1422. doi:10.3390/cancers11101422

Evstafieva, A. G., Garaeva, A. A., Khutornenko, A. A., Klepikova, A. V., Logacheva, M. D., Penin, A. A., et al. (2014). A Sustained Deficiency of Mitochondrial Respiratory Complex III Induces an Apoptotic Cell Death through the P53Mediated Inhibition of Pro-survival Activities of the Activating Transcription Factor 4. Cell Death Dis. 5, e1511. doi:10.1038/cddis.2014.469

Galehdar, Z., Swan, P., Fuerth, B., Callaghan, S. M., Park, D. S., and Cregan, S. P. (2010). Neuronal Apoptosis Induced by Endoplasmic Reticulum Stress Is Regulated by ATF4-CHOP-Mediated Induction of the Bcl-2 Homology 3only Member PUMA. J. Neurosci. 30 (50), 16938-16948. doi:10.1523/ JNEUROSCI.1598-10.2010

Hamanaka, R. B., Bobrovnikova-Marjon, E., Ji, X., Liebhaber, S. A., and Diehl, J. A. (2009). PERK-dependent Regulation of IAP Translation during ER Stress. Oncogene 28 (6), 910-920. doi:10.1038/onc.2008.428

Hamidi, T., Cano, C. E., Grasso, D., Garcia, M. N., Sandi, M. J., Calvo, E. L., et al. (2012). Nupr1-aurora Kinase A Pathway Provides protection against Metabolic Stress-Mediated Autophagic-Associated Cell Death. Clin. Cancer Res. 18 (19), 5234-5246. doi:10.1158/1078-0432.CCR-12-0026

Han, A. P., Yu, C., Lu, L., Fujiwara, Y., Browne, C., Chin, G., et al. (2001). Hemeregulated eIF2alpha Kinase (HRI) Is Required for Translational Regulation and Survival of Erythroid Precursors in Iron Deficiency. EMBO J. 20 (23), 6909-6918. doi:10.1093/emboj/20.23.6909

Harding, H. P., Novoa, I., Zhang, Y., Zeng, H., Wek, R., Schapira, M., et al. (2000). Regulated Translation Initiation Controls Stress-Induced Gene Expression in Mammalian Cells. Mol. Cel. 6 (5), 1099-1108. doi:10.1016/s1097-2765(00) 00108-8

Hartleben, G., Schorpp, K., Kwon, Y., Betz, B., Tsokanos, F. F., Dantes, Z., et al. (2021). Combination Therapies Induce Cancer Cell Death through the Integrated Stress Response and Disturbed Pyrimidine Metabolism. EMBO Mol. Med. 13 (4), e12461. doi:10.15252/emmm.202012461

Ho, K. H., Lee, Y. T., Chen, P. H., Shih, C. M., Cheng, C. H., and Chen, K. C. (2021). Guanabenz Sensitizes Glioblastoma Cells to Sunitinib by Inhibiting GADD34Mediated Autophagic Signaling. Neurotherapeutics 18, 1371-1392. doi:10.1007/ s13311-020-00961-z
Hu, J., Dang, N., Menu, E., De Bruyne, E., De Bryune, E., Xu, D., et al. (2012). Activation of ATF4 Mediates Unwanted Mcl-1 Accumulation by Proteasome Inhibition. Blood 119 (3), 826-837. doi:10.1182/blood-2011-07-366492

Hu, P., Han, Z., Couvillon, A. D., and Exton, J. H. (2004). Critical Role of Endogenous Akt/IAPs and MEK1/ERK Pathways in Counteracting Endoplasmic Reticulum Stress-Induced Cell Death. J. Biol. Chem. 279 (47), 49420-49429. doi:10.1074/jbc.M407700200

Hu, W., Hofstetter, W., Wei, X., Guo, W., Zhou, Y., Pataer, A., et al. (2009). Double-stranded RNA-dependent Protein Kinase-dependent Apoptosis Induction by a Novel Small Compound. J. Pharmacol. Exp. Ther. 328 (3), 866-872. doi:10.1124/jpet.108.141754

Huang, Z., and Hu, H. (2021). Arginine Deiminase Induces Immunogenic Cell Death and Is Enhanced by N-Acetylcysteine in Murine MC38 Colorectal Cancer Cells and MDA-MB-231 Human Breast Cancer Cells In Vitro. Molecules 26 (2). doi:10.3390/molecules 26020511

Ill-Raga, G., Tajes, M., Busquets-García, A., Ramos-Fernández, E., Vargas, L. M., BoschMorató, M., et al. (2015). Physiological Control of Nitric Oxide in Neuronal BACE1 Translation by Heme-Regulated eIF2 $\alpha$ Kinase HRI Induces Synaptogenesis. Antioxid. Redox Signal. 22 (15), 1295-1307. doi:10.1089/ars.2014.6080

Ishizawa, J., Kojima, K., Chachad, D., Ruvolo, P., Ruvolo, V., Jacamo, R. O., et al. (2016). ATF4 Induction through an Atypical Integrated Stress Response to ONC201 Triggers P53-independent Apoptosis in Hematological Malignancies. Sci. Signal. 9 (415), ra17. doi:10.1126/scisignal.aac4380

Jammi, N. V., Whitby, L. R., and Beal, P. A. (2003). Small Molecule Inhibitors of the RNA-dependent Protein Kinase. Biochem. Biophys. Res. Commun. 308 (1), 50-57. doi:10.1016/s0006-291x(03)01318-4

Jin, H. O., Seo, S. K., Woo, S. H., Choe, T. B., Hong, S. I., Kim, J. I., et al. (2009). Nuclear Protein 1 Induced by ATF4 in Response to Various Stressors Acts as a Positive Regulator on the Transcriptional Activation of ATF4. IUBMB Life. 61 (12), 1153-1158. doi:10.1002/iub.271

Karpel-Massler, G., Horst, B. A., Shu, C., Chau, L., Tsujiuchi, T., Bruce, J. N., et al. (2016). A Synthetic Cell-Penetrating Dominant-Negative ATF5 Peptide Exerts Anticancer Activity against a Broad Spectrum of Treatment-Resistant Cancers. Clin. Cancer Res. 22 (18), 4698-4711. doi:10.1158/1078-0432.CCR-15-2827

Kasai, S., Yamazaki, H., Tanji, K., Engler, M. J., Matsumiya, T., and Itoh, K. (2019). Role of the ISR-ATF4 Pathway and its Cross Talk with Nrf2 in Mitochondrial Quality Control. J. Clin. Biochem. Nutr. 64 (1), 1-12. doi:10.3164/jcbn.18-37

Kato, Y., Kunimasa, K., Sugimoto, Y., and Tomida, A. (2018). BCR-ABL Tyrosine Kinase Inhibition Induces Metabolic Vulnerability by Preventing the Integrated Stress Response in K562 cells. Biochem. Biophys. Res. Commun. 504 (4), 721-726. doi:10.1016/j.bbrc.2018.09.032

Kazemi, S., Mounir, Z., Baltzis, D., Raven, J. F., Wang, S., Krishnamoorthy, J. L., et al. (2007). A Novel Function of eIF2alpha Kinases as Inducers of the Phosphoinositide-3 Kinase Signaling Pathway. Mol. Biol. Cel. 18 (9), 3635-3644. doi:10.1091/mbc.e07-01-0053

Kim, R. H., Coates, J. M., Bowles, T. L., McNerney, G. P., Sutcliffe, J., Jung, J. U., et al. (2009). Arginine Deiminase as a Novel Therapy for Prostate Cancer Induces Autophagy and Caspase-independent Apoptosis. Cancer Res. 69 (2), 700-708. doi:10.1158/0008-5472.CAN-08-3157

Kim, T. W., Cheon, C., and Ko, S. G. (2020). SH003 Activates Autophagic Cell Death by Activating ATF4 and Inhibiting G9a under Hypoxia in Gastric Cancer Cells. Cel Death Dis. 11 (8), 717. doi:10.1038/s41419-020-02924-w

Kline, C. L., Van den Heuvel, A. P., Allen, J. E., Prabhu, V. V., Dicker, D. T., and ElDeiry, W. S. (2016). ONC201 Kills Solid Tumor Cells by Triggering an Integrated Stress Response Dependent on ATF4 Activation by Specific eIF2a Kinases. Sci. Signal. 9 (415), ra18. doi:10.1126/scisignal.aac4374

Kouroku, Y., Fujita, E., Tanida, I., Ueno, T., Isoai, A., Kumagai, H., et al. (2007). ER Stress (PERK/eIF2alpha Phosphorylation) Mediates the PolyglutamineInduced LC3 Conversion, an Essential Step for Autophagy Formation. Cel Death Differ. 14 (2), 230-239. doi:10.1038/sj.cdd.4401984

Kroemer, G., Mariño, G., and Levine, B. (2010). Autophagy and the Integrated Stress Response. Mol. Cel. 40 (2), 280-293. doi:10.1016/ j.molcel.2010.09.023

Lamora, A., Mullard, M., Amiaud, J., Brion, R., Heymann, D., Redini, F., et al. (2015). Anticancer Activity of Halofuginone in a Preclinical Model of Osteosarcoma: Inhibition of Tumor Growth and Lung Metastases. Oncotarget 6 (16), 14413-14427. doi:10.18632/oncotarget.3891 
Lee, Y. Y., Cevallos, R. C., and Jan, E. (2009). An Upstream Open reading Frame Regulates Translation of GADD34 during Cellular Stresses that Induce eIF2alpha Phosphorylation. J. Biol. Chem. 284 (11), 6661-6673. doi:10.1074/jbc.M806735200

Li, T., Su, L., Lei, Y., Liu, X., Zhang, Y., and Liu, X. (2015). DDIT3 and KAT2A Proteins Regulate TNFRSF10A and TNFRSF10B Expression in Endoplasmic Reticulum Stress-Mediated Apoptosis in Human Lung Cancer Cells. J. Biol. Chem. 290 (17), 11108-11118. doi:10.1074/jbc.M115.645333

Liu, D. X., Qian, D., Wang, B., Yang, J. M., and Lu, Z. (2011). p300-Dependent ATF5 Acetylation Is Essential for Egr-1 Gene Activation and Cell Proliferation and Survival. Mol. Cel Biol. 31 (18), 3906-3916. doi:10.1128/MCB.05887-11

Long, Y., Tsai, W. B., Wangpaichitr, M., Tsukamoto, T., Savaraj, N., Feun, L. G., et al. (2013). Arginine Deiminase Resistance in Melanoma Cells Is Associated with Metabolic Reprogramming, Glucose Dependence, and Glutamine Addiction. Mol. Cancer Ther. 12 (11), 2581-2590. doi:10.1158/15357163.MCT-13-0302

Lu, L., Han, A. P., and Chen, J. J. (2001). Translation Initiation Control by HemeRegulated Eukaryotic Initiation Factor 2alpha Kinase in Erythroid Cells under Cytoplasmic Stresses. Mol. Cel Biol. 21 (23), 7971-7980. doi:10.1128/ MCB.21.23.7971-7980.2001

Lu, M., Lawrence, D. A., Marsters, S., Acosta-Alvear, D., Kimmig, P., Mendez, A. S., et al. (2014). Opposing Unfolded-Protein-Response Signals Converge on Death Receptor 5 to Control Apoptosis. Science 345 (6192), 98-101. doi:10.1126/ science. 1254312

Lv, S., Sun, E. C., Xu, Q. Y., Zhang, J. K., and Wu, D. L. (2015). Endoplasmic Reticulum Stress-Mediated Autophagy Contributes to Bluetongue Virus Infection via the PERK-eIF2a Pathway. Biochem. Biophys. Res. Commun. 466 (3), 406-412. doi:10.1016/j.bbrc.2015.09.039

Mahadevan, N. R., Rodvold, J., Sepulveda, H., Rossi, S., Drew, A. F., and Zanetti, M. (2011). Transmission of Endoplasmic Reticulum Stress and Pro-inflammation from Tumor Cells to Myeloid Cells. Proc. Natl. Acad. Sci. U S A. 108 (16), 6561-6566. doi:10.1073/pnas.1008942108

Martin, T. A., Li, A. X., Sanders, A. J., Ye, L., Frewer, K., Hargest, R., et al. (2021). NUPR1 and its Potential Role in Cancer and Pathological Conditions (Review). Int. J. Oncol. 58 (5). doi:10.3892/ijo.2021.5201

McConkey, D. J. (2017). The Integrated Stress Response and Proteotoxicity in Cancer Therapy. Biochem. Biophys. Res. Commun. 482 (3), 450-453. doi:10.1016/j.bbrc.2016.11.047

McEwen, E., Kedersha, N., Song, B., Scheuner, D., Gilks, N., Han, A., et al. (2005). Heme-regulated Inhibitor Kinase-Mediated Phosphorylation of Eukaryotic Translation Initiation Factor 2 Inhibits Translation, Induces Stress Granule Formation, and Mediates Survival upon Arsenite Exposure. J. Biol. Chem. 280 (17), 16925-16933. doi:10.1074/jbc.M412882200

Milani, M., Rzymski, T., Mellor, H. R., Pike, L., Bottini, A., Generali, D., et al. (2009). The Role of ATF4 Stabilization and Autophagy in Resistance of Breast Cancer Cells Treated with Bortezomib. Cancer Res. 69 (10), 4415-4423. doi:10.1158/0008-5472.CAN-08-2839

Mohamed, E., Sierra, R. A., Trillo-Tinoco, J., Cao, Y., Innamarato, P., Payne, K. K., et al. (2020). The Unfolded Protein Response Mediator PERK Governs Myeloid Cell-Driven Immunosuppression in Tumors through Inhibition of STING Signaling. Immunity 52 (4), 668-e7. doi:10.1016/j.immuni.2020.03.004

Mukherjee, T., Ramaglia, V., Abdel-Nour, M., Bianchi, A. A., Tsalikis, J., Chau, H. N., et al. (2021). The eIF2 $\alpha$ Kinase HRI Triggers the Autophagic Clearance of Cytosolic Protein Aggregates. J. Biol. Chem. 296, 100050. doi:10.1074/jbc.RA120.014415

Narita, T., Ri, M., Masaki, A., Mori, F., Ito, A., Kusumoto, S., et al. (2015). Lower Expression of Activating Transcription Factors 3 and 4 Correlates with Shorter Progression-free Survival in Multiple Myeloma Patients Receiving Bortezomib Plus Dexamethasone Therapy. Blood Cancer J. 5, e373. doi: $10.1038 /$ bcj. 2015.98

Nguyen, T. H., Koneru, B., Wei, S. J., Chen, W. H., Makena, M. R., Urias, E., et al. (2019). Fenretinide via NOXA Induction, Enhanced Activity of the BCL-2 Inhibitor Venetoclax in High BCL-2-Expressing Neuroblastoma Preclinical Models. Mol. Cancer Ther. 18 (12), 2270-2282. doi:10.1158/1535-7163.MCT-19-0385

Núñez-Vázquez, S., Sánchez-Vera, I., Saura-Esteller, J., Cosialls, A. M., Noisier, A. F. M., Albericio, F., et al. (2021). NOXA Upregulation by the ProhibitinBinding Compound Fluorizoline Is Transcriptionally Regulated by Integrated Stress Response-Induced ATF3 and ATF4. FEBS J. 288 (4), 1271-1285. doi:10.1111/febs.15480
O'Malley, J., Kumar, R., Inigo, J., Yadava, N., and Chandra, D. (2020). Mitochondrial Stress Response and Cancer. Trends Cancer. 6 (8), 688-701. doi:10.1016/j.trecan.2020.04.009

Obeng, E. A., Carlson, L. M., Gutman, D. M., Harrington, W. J., Lee, K. P., and Boise, L. H. (2006). Proteasome Inhibitors Induce a Terminal Unfolded Protein Response in Multiple Myeloma Cells. Blood 107 (12), 4907-4916. doi:10.1182/ blood-2005-08-3531

Obiedat, A., Charpak-Amikam, Y., Tai-Schmiedel, J., Seidel, E., Mahameed, M., Avril, T., et al. (2020). The Integrated Stress Response Promotes B7H6 Expression. J. Mol. Med. (Berl) 98 (1), 135-148. doi:10.1007/s00109-019-01859-w

Ohoka, N., Yoshii, S., Hattori, T., Onozaki, K., and Hayashi, H. (2005). TRB3, a Novel ER Stress-Inducible Gene, Is Induced via ATF4-CHOP Pathway and Is Involved in Cell Death. EMBO J. 24 (6), 1243-1255. doi:10.1038/sj.emboj.7600596

Ojha, R., Leli, N. M., Onorati, A., Piao, S., Verginadis, I. I., Tameire, F., et al. (2019). ER Translocation of the MAPK Pathway Drives Therapy Resistance in BRAF-Mutant Melanoma. Cancer Discov. 9 (3), 396-415. doi:10.1158/2159-8290.CD-18-0348

Orvedahl, A., Alexander, D., Tallóczy, Z., Sun, Q., Wei, Y., Zhang, W., et al. (2007). HSV-1 ICP34.5 Confers Neurovirulence by Targeting the Beclin 1 Autophagy Protein. Cell Host Microbe. 1 (1), 23-35. doi:10.1016/j.chom.2006.12.001

Pakos-Zebrucka, K., Koryga, I., Mnich, K., Ljujic, M., Samali, A., and Gorman, A. M. (2016). The Integrated Stress Response. EMBO Rep. 17 (10), 1374-1395. doi:10.15252/embr.201642195

Palam, L. R., Baird, T. D., and Wek, R. C. (2011). Phosphorylation of eIF2 Facilitates Ribosomal Bypass of an Inhibitory Upstream ORF to Enhance CHOP Translation. J. Biol. Chem. 286 (13), 10939-10949. doi:10.1074/jbc.M110.216093

Palam, L. R., Gore, J., Craven, K. E., Wilson, J. L., and Korc, M. (2015). Integrated Stress Response Is Critical for Gemcitabine Resistance in Pancreatic Ductal Adenocarcinoma. Cel Death Dis. 6 (10), e1913. doi:10.1038/cddis.2015.264

Perkins, D. J., and Barber, G. N. (2004). Defects in Translational Regulation Mediated by the Alpha Subunit of Eukaryotic Initiation Factor 2 Inhibit Antiviral Activity and Facilitate the Malignant Transformation of Human Fibroblasts. Mol. Cel Biol. 24 (5), 2025-2040. doi:10.1128/mcb.24.5.2025-2040.2004

Puthalakath, H., O’Reilly, L. A., Gunn, P., Lee, L., Kelly, P. N., Huntington, N. D., et al. (2007). ER Stress Triggers Apoptosis by Activating BH3-Only Protein Bim. Cell 129 (7), 1337-1349. doi:10.1016/j.cell.2007.04.027

Robert, F., Williams, C., Yan, Y., Donohue, E., Cencic, R., Burley, S. K., et al. (2009). Blocking UV-Induced eIF2alpha Phosphorylation with Small Molecule Inhibitors of GCN2. Chem. Biol. Drug Des. 74 (1), 57-67. doi:10.1111/ j.1747-0285.2009.00827.x

Rosen, M. D., Woods, C. R., Goldberg, S. D., Hack, M. D., Bounds, A. D., Yang, Y., et al. (2009). Discovery of the First Known Small-Molecule Inhibitors of HemeRegulated Eukaryotic Initiation Factor 2alpha (HRI) Kinase. Bioorg. Med. Chem. Lett. 19 (23), 6548-6551. doi:10.1016/j.bmcl.2009.10.033

Rouschop, K. M., Dubois, L. J., Keulers, T. G., van den Beucken, T., Lambin, P., Bussink, J., et al. (2013). PERK/eIF2a Signaling Protects Therapy Resistant Hypoxic Cells through Induction of Glutathione Synthesis and protection against ROS. Proc. Natl. Acad. Sci. U S A. 110 (12), 4622-4627. doi:10.1073/pnas.1210633110

Rouschop, K. M., van den Beucken, T., Dubois, L., Niessen, H., Bussink, J., Savelkouls, K., et al. (2010). The Unfolded Protein Response Protects Human Tumor Cells during Hypoxia through Regulation of the Autophagy Genes MAP1LC3B and ATG5. J. Clin. Invest. 120 (1), 127-141. doi:10.1172/JCI40027

Rzymski, T., Milani, M., Pike, L., Buffa, F., Mellor, H. R., Winchester, L., et al. (2010). Regulation of Autophagy by ATF4 in Response to Severe Hypoxia. Oncogene 29 (31), 4424-4435. doi:10.1038/onc.2010.191

Rzymski, T., Milani, M., Singleton, D. C., and Harris, A. L. (2009). Role of ATF4 in Regulation of Autophagy and Resistance to Drugs and Hypoxia. Cell Cycle. 8 (23), 3838-3847. doi:10.4161/cc.8.23.10086

Santofimia-Castaño, P., Lan, W., Bintz, J., Gayet, O., Carrier, A., Lomberk, G., et al. (2018). Inactivation of NUPR1 Promotes Cell Death by Coupling ER-Stress Responses with Necrosis. Sci. Rep. 8 (1), 16999. doi:10.1038/s41598-018-35020-3

Sasaki, K., Uchiumi, T., Toshima, T., Yagi, M., Do, Y., Hirai, H., et al. (2020). Mitochondrial Translation Inhibition Triggers ATF4 Activation, Leading to Integrated Stress Response but Not to Mitochondrial Unfolded Protein Response. Biosci. Rep. 40 (11). doi:10.1042/BSR20201289

Sharma, K., Vu, T. T., Cook, W., Naseri, M., Zhan, K., Nakajima, W., et al. (2018). p53-independent Noxa Induction by Cisplatin Is Regulated by ATF3/ATF4 in Head and Neck Squamous Cell Carcinoma Cells. Mol. Oncol. 12 (6), 788-798. doi:10.1002/1878-0261.12172 
Shen, S., Niso-Santano, M., Adjemian, S., Takehara, T., Malik, S. A., Minoux, H., et al. (2012). Cytoplasmic STAT3 Represses Autophagy by Inhibiting PKR Activity. Mol. Cel. 48 (5), 667-680. doi:10.1016/j.molcel.2012.09.013

Sidrauski, C., McGeachy, A. M., Ingolia, N. T., and Walter, P. (2015). The Small Molecule ISRIB Reverses the Effects of eIF2 $\alpha$ Phosphorylation on Translation and Stress Granule Assembly. Elife 4. doi:10.7554/eLife.05033

Singh, P. K., Deorukhkar, A. A., Venkatesulu, B. P., Li, X., Tailor, R., Bomalaski, J. S., et al. (2019). Exploiting Arginine Auxotrophy with Pegylated Arginine Deiminase (ADI-PEG20) to Sensitize Pancreatic Cancer to Radiotherapy via Metabolic Dysregulation. Mol. Cancer Ther. 18 (12), 2381-2393. doi:10.1158/ 1535-7163.MCT-18-0708

Smyth, R., Berton, S., Rajabalee, N., Chan, T., and Sun, J. (2020). Protein Kinase R Restricts the Intracellular Survival of Mycobacterium tuberculosis by Promoting Selective Autophagy. Front. Microbiol. 11, 613963. doi:10.3389/fmicb.2020.613963

Spector, I., Honig, H., Kawada, N., Nagler, A., Genin, O., and Pines, M. (2010). Inhibition of Pancreatic Stellate Cell Activation by Halofuginone Prevents Pancreatic Xenograft Tumor Development. Pancreas 39 (7), 1008-1015. doi:10.1097/MPA.0b013e3181da8aa3

Stockwell, S. R., Platt, G., Barrie, S. E., Zoumpoulidou, G., Te Poele, R. H., Aherne, G. W., et al. (2012). Mechanism-based Screen for G1/S Checkpoint Activators Identifies a Selective Activator of EIF2AK3/PERK Signalling. PLoS One 7 (1), e28568. doi:10.1371/journal.pone.0028568

Stone, S., Ho, Y., Li, X., Jamison, S., Harding, H. P., Ron, D., et al. (2016). Dual Role of the Integrated Stress Response in Medulloblastoma Tumorigenesis. Oncotarget 7 (39), 64124-64135. doi:10.18632/oncotarget.11873

Suragani, R. N., Zachariah, R. S., Velazquez, J. G., Liu, S., Sun, C. W., Townes, T. M., et al. (2012). Heme-regulated eIF2 $\alpha$ Kinase Activated Atf4 Signaling Pathway in Oxidative Stress and Erythropoiesis. Blood 119 (22), 5276-5284. doi:10.1182/ blood-2011-10-388132

Suraweera, A., Münch, C., Hanssum, A., and Bertolotti, A. (2012). Failure of Amino Acid Homeostasis Causes Cell Death Following Proteasome Inhibition. Mol. Cel. 48 (2), 242-253. doi:10.1016/j.molcel.2012.08.003

Suresh, S., Chen, B., Zhu, J., Golden, R. J., Lu, C., Evers, B. M., et al. (2020). eIF5B Drives Integrated Stress Response-dependent Translation of PD-L1 in Lung Cancer. Nat. Cancer. 1 (5), 533-545. doi:10.1038/s43018-020-0056-0

Tallóczy, Z., Jiang, W., Virgin, H. W., Leib, D. A., Scheuner, D., Kaufman, R. J., et al. (2002). Regulation of Starvation- and Virus-Induced Autophagy by the eIF2alpha Kinase Signaling Pathway. Proc. Natl. Acad. Sci. U S A. 99 (1), 190-195. doi:10.1073/pnas.012485299

Tallóczy, Z., Virgin, H. W., and Levine, B. (2006). PKR-dependent Autophagic Degradation of Herpes Simplex Virus Type 1. Autophagy 2 (1), 24-29. doi:10.4161/auto.2176

Tameire, F., Verginadis, I. I., Leli, N. M., Polte, C., Conn, C. S., Ojha, R., et al. (2019). ATF4 Couples MYC-dependent Translational Activity to Bioenergetic Demands during Tumour Progression. Nat. Cel Biol. 21 (7), 889-899. doi:10.1038/s41556-019-0347-9

Tian, X., Ahsan, N., Lulla, A., Lev, A., Abbosh, P., Dicker, D. T., et al. (2021). P53independent Partial Restoration of the P53 Pathway in Tumors with Mutated P53 through ATF4 Transcriptional Modulation by ERK1/2 and CDK9. Neoplasia 23 (3), 304-325. doi:10.1016/j.neo.2021.01.004

Tsaytler, P., Harding, H. P., Ron, D., and Bertolotti, A. (2011). Selective Inhibition of a Regulatory Subunit of Protein Phosphatase 1 Restores Proteostasis. Science 332 (6025), 91-94. doi:10.1126/science.1201396

Wang, C., Zhu, J. B., Yan, Y. Y., Zhang, W., Gong, X. J., Wang, X., et al. (2020). Halofuginone Inhibits Tumorigenic Progression of 5-FU-Resistant Human Colorectal Cancer HCT-15/FU Cells by Targeting miR-132-3p In Vitro. Oncol. Lett. 20 (6), 385. doi:10.3892/ol.2020.12248

Wang, S., Chen, X. A., Hu, J., Jiang, J. K., Li, Y., Chan-Salis, K. Y., et al. (2015). ATF4 Gene Network Mediates Cellular Response to the Anticancer PAD Inhibitor YW3-56 in Triple-Negative Breast Cancer Cells. Mol. Cancer Ther. 14 (4), 877-888. doi:10.1158/1535-7163.MCT-14-1093-T

Warnakulasuriyarachchi, D., Cerquozzi, S., Cheung, H. H., and Holcík, M. (2004). Translational Induction of the Inhibitor of Apoptosis Protein HIAP2 during
Endoplasmic Reticulum Stress Attenuates Cell Death and Is Mediated via an Inducible Internal Ribosome Entry Site Element. J. Biol. Chem. 279 (17), 17148-17157. doi:10.1074/jbc.M308737200

Wek, R. C., Jiang, H. Y., and Anthony, T. G. (2006). Coping with Stress: eIF2 Kinases and Translational Control. Biochem. Soc. Trans. 34 (Pt 1), 7-11. doi:10.1042/BST20060007

Whitney, M. L., Jefferson, L. S., and Kimball, S. R. (2009). ATF4 Is Necessary and Sufficient for ER Stress-Induced Upregulation of REDD1 Expression. Biochem. Biophys. Res. Commun. 379 (2), 451-455. doi:10.1016/ j.bbrc.2008.12.079

Wortel, I. M. N., van der Meer, L. T., Kilberg, M. S., and van Leeuwen, F. N. (2017). Surviving Stress: Modulation of ATF4-Mediated Stress Responses in Normal and Malignant Cells. Trends Endocrinol. Metab. 28 (11), 794-806. doi:10.1016/ j.tem.2017.07.003

Ye, J., Kumanova, M., Hart, L. S., Sloane, K., Zhang, H., De Panis, D. N., et al. (2010). The GCN2-ATF4 Pathway Is Critical for Tumour Cell Survival and Proliferation in Response to Nutrient Deprivation. EMBO J. 29 (12), 2082-2096. doi:10.1038/emboj.2010.81

Yerlikaya, A., Kimball, S. R., and Stanley, B. A. (2008). Phosphorylation of eIF2alpha in Response to 26S Proteasome Inhibition Is Mediated by the Haem-Regulated Inhibitor (HRI) Kinase. Biochem. J. 412 (3), 579-588. doi:10.1042/BJ20080324

Yuniati, L., van der Meer, L. T., Tijchon, E., van Ingen Schenau, D., van Emst, L., Levers, M., et al. (2016). Tumor Suppressor BTG1 Promotes PRMT1-Mediated ATF4 Function in Response to Cellular Stress. Oncotarget 7 (3), 3128-3143. doi:10.18632/oncotarget.6519

Zhang, S., Macias-Garcia, A., Velazquez, J., Paltrinieri, E., Kaufman, R. J., and Chen, J. J. (2018). HRI Coordinates Translation by eIF2 $\alpha \mathrm{P}$ and mTORC1 to Mitigate Ineffective Erythropoiesis in Mice during Iron Deficiency. Blood 131 (4), 450-461. doi:10.1182/blood-2017-08-799908

Zhang, Y., Zhou, L., Safran, H., Borsuk, R., Lulla, R., Tapinos, N., et al. (2021). EZH2i EPZ-6438 and HDACi Vorinostat Synergize with ONC201/TIC10 to Activate Integrated Stress Response, DR5, Reduce H3K27 Methylation, ClpX and Promote Apoptosis of Multiple Tumor Types Including DIPG. Neoplasia 23 (8), 792-810. doi:10.1016/j.neo.2021.06.007

Zhou, D., Palam, L. R., Jiang, L., Narasimhan, J., Staschke, K. A., and Wek, R. C. (2008). Phosphorylation of eIF2 Directs ATF5 Translational Control in Response to Diverse Stress Conditions. J. Biol. Chem. 283 (11), 7064-7073. doi:10.1074/jbc.M708530200

Conflict of Interest: WE-D. is a co-founder of Oncoceutics, Inc., a subsidiary of Chimerix, and a Founder of p53-Therapeutics. WE-D has disclosed his relationship with these companies and potential conflict of interest to his academic institution/employer and is fully compliant with NIH and institutional policy that is managing this potential conflict of interest.

The remaining authors declare that the research was conducted in the absence of any commercial or financial relationships that could be construed as a potential conflict of interest.

Publisher's Note: All claims expressed in this article are solely those of the authors and do not necessarily represent those of their affiliated organizations, or those of the publisher, the editors and the reviewers. Any product that may be evaluated in this article, or claim that may be made by its manufacturer, is not guaranteed or endorsed by the publisher.

Copyright $\odot 2021$ Tian, Zhang, Zhou, Seyhan, Hernandez Borrero, Zhang and ElDeiry. This is an open-access article distributed under the terms of the Creative Commons Attribution License (CC BY). The use, distribution or reproduction in other forums is permitted, provided the original author(s) and the copyright owner(s) are credited and that the original publication in this journal is cited, in accordance with accepted academic practice. No use, distribution or reproduction is permitted which does not comply with these terms. 